\title{
A physical model study of surrounding rock failure near a fault under the influence of footwall coal mining
}

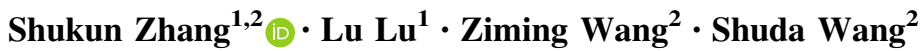

Received: 4 March 2020/Revised: 6 June 2020/Accepted: 27 October 2020/Published online: 22 November 2020

(C) The Author(s) 2020

\begin{abstract}
A study of the deformation of the surrounding rock and coal pillars near a fault under the influence of mining is conducted on a physical model for the design of coal pillars to support and maintain the roofs of adjacent fault roadways. This research is based on the 15101 mining face in the Baiyangling Coal Mine, Shanxi, China, and uses simulation tests similar to digital speckle test technology to analyse the displacement, strain and vertical stress fields of surrounding rocks near faults to determine the influence of the coal pillar width. The results are as follows. The surrounding rock of the roadway roof fails to form a balance hinge for the massive rock mass. The vertical displacement, vertical strain and other deformation of the surrounding rock near the fault increase steeply as the coal pillar width decreases. The steep increase in deformation corresponds to a coal pillar width of $10 \mathrm{~m}$. When the coal pillar width is $7.5 \mathrm{~m}$, the pressure on the surrounding rock near the footwall of the fault suddenly increases, while the pressure on the hanging wall near the fault increases by only $0.35 \mathrm{MPa}$. The stress of the rock mass of the hanging wall is not completely shielded by the fault, and part of the load disturbance is still transmitted to the hanging wall via friction. The width of the fault coal pillars at the 15101 working face is determined to be $7.5 \mathrm{~m}$, and the monitoring data verify the rationality of the fault coal pillars.
\end{abstract}

Keywords Fault $\cdot$ Mining roadway $\cdot$ Surrounding rock $\cdot$ Coal pillar $\cdot$ Physical model

\section{Introduction}

Coal mining often encounters geological environments with complex structures and faults. When the working face boundary is a fault, to greatly improve the mining production, the coal pillars left between the mining roadways and the faults are often small, and sometimes, no coal pillars are left. Fault cutting disrupts the integrity of the rock strata and has a significant impact on the distribution of mining-induced pressure. The influence of disturbance stress is likely to cause fault activation, coal pillar or

Shukun Zhang

4254423@163.com

1 School of City and Architecture Engineering, Zaozhuang University, Zaozhuang 277160, Shandong, China

2 School of Civil Engineering, Liaoning Technical University, Fuxin 123000, Liaoning, China roadway failure near the fault, surrounding rock deformation, and roof falls, and it can even impact rock burst accidents. The study of the deformation characteristics of faults and coal pillars during the mining process has important value for maintaining and control of the roof and the design of coal pillars (Jiang et al. 2014).

At present, scholars have performed fruitful research on mining-induced pressure in surrounding rocks near faults and the deformation and failure of fault roadways. Islam and Shinjo (2009) used numerical simulation methods to establish the relation between the location of a haulage roadway and the fault position and noted that deviatoric stress is the main reason for block failure in the surrounding rock. Chen et al. (2012) analysed the characteristics of monitored microseismic signals in surrounding rocks when the mining face passed through a fault and found that low-energy shock is a manifestation of the energy accumulation trend of strong earthquakes. They 
also evaluated the possibility of rock burst near the fault. $\mathrm{Ji}$ et al. (2012) analysed the influence of mining disturbance on the stress environment of the fault by proposing the dynamic Coulomb failure stress model. Li et al. (2014) established a fault-coal pillar mechanical model and obtained a roof instability criterion. Wang et al. (2016) and Wang et al. (2019) used abrupt stress and abrupt displacement information to determine whether a fault was activated and designed a new anchor support method. Wang et al. (2017) used tomography to study the sliding mechanism of a fault during underground mining and found that the time interval between two fault slips has a positive correlation with the energy released therein. Piotr et al. (2017) took the occurrence of fault roadway failure and supporting deformation as the research object to numerically analyse the influence law of faults affecting the deformation of roadway surrounding rock via dozens of rock mass parameters. The research showed that the influence of faults on the surrounding rock of the roadway is four times greater than that on the unaffected surrounding rock, on average. Sainoki and Mitri (2017) studied the failure law of the intersection of deep geological faults and steeply inclined orebodies and revealed that the influence of the mining direction on fault activation decreases significantly as the fault dip angle decreases. Das et al. (2018) simulated several cases of mining roadway instability caused by faults in India and proposed that fault dips and friction angles are the main factors affecting the strength of coal pillars and the stability of roadways. Yang et al. (2019) used the Universal Discrete Element Code (UDEC) to simulate the deformation process of surrounding rock under different fracture positions and analyse the stability of the surrounding rock structure during non-coal pillar mining with roadway formed automatically (RFANM). Zhang et al. (2018) studied the weakening action of faults on the mechanical properties of surrounding rocks and adopted high-strength combined support measures to suppress the occurrence of large deformations in fault roadways. Lu et al. (2019) took the high-shear stress area on the triggered fault plane as the research object and established the correlation between microseismic source parameters and fault slips, providing a basis for fault slip-induced shock pressure early warning and control in coal mines. Yin et al. (2019) used FLAC3D to simulate the fault activation process and proposed that the maximum displacement of the hanging wall and footwall of the fault is related to the roof water-conducting fractured zone and the floor damage zone. Kumar et al. (2019) used field research and indoor numerical modelling and revealed that the modulus of elasticity and the thicknesses of the immediate roof can be used as important parameters in determining the warning value of the roof sagging and that the variation in the size of the left-out ribs and goaf span also influence the warning value.

The research outcomes above mainly focused on aspects such as the stress state of the fault, the supporting method of the roadway near the fault, and the law of rock burst induced by fault activation. The monitoring and research objects were mostly faults, faults and roadways, faults and coal pillars, or faults and roofs. Furthermore, when mining in the vicinity of a fault, the faults, coal pillars, and roadways in the surrounding rock near the fault are interdependent, and the stability of these structures jointly controls the stability of the surrounding rock near the fault. Determining the impact of mining activities on the stress, deformation, and failure of these structures and the stress and deformation characteristics of the surrounding rocks near the fault will reveal the mechanism of fault activation under mining conditions. More research on these topics is needed.

Therefore, this paper takes the geological conditions of the Baiyangling Coal Mine as the example and conducts similar simulation tests. The use of digital speckle testing technology in conjunction with a surrounding rock pressure acquisition system can achieve the high-speed synchronous acquisition of model data under non-contact conditions. The test system can reproduce the deformation and failure of the surrounding rocks of faults, coal pillars and nearby roadways under mining conditions, effectively avoiding the simulation errors caused by the use of too many assumptions in a numerical simulation. At the same time, it is difficult to comprehensively and synchronously collect data related to faults, coal pillars and surrounding roadway rocks during actual engineering monitoring, but this situation is avoided. Using digital speckle technology and the non-contact collection of surface deformation data form similar test models avoids interference with the model deformation process and improves the accuracy of the test simulation. The results of the study provide scientific guidance for the mining production of ore bodies near faults.

\section{Load transmission characteristics of mining under a normal fault footwall}

When the working surface of a normal fault footwall is mined, the hinge structure after the main roof fault block in the goaf will move, as shown in Fig. 1.

Here, $h_{\mathrm{c}}$ is the thickness of the main roof, $\mathrm{m} ; h_{\mathrm{z}}$ is the thickness of the rock layer of the immediate roof, $\mathrm{m} ; \mathrm{m}$ is the thickness of the coal seam; $T$ is the contact stress of the fault block, MN/m; $L$ is the length of the main roof rotational fault block in the goaf that is transferred to the main roof fault block above the coal pillar, $\mathrm{m} ; q$ is the total load 


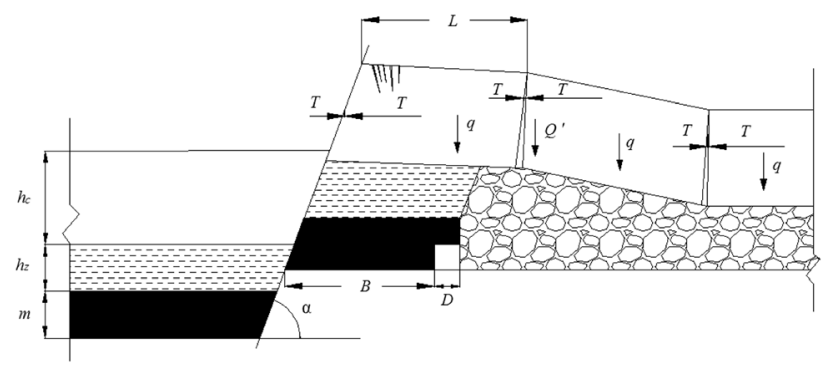

Fig. 1 Block structure of normal fault footwall mining (Dai and Jiang 2016)

of the overlying load layer and the current layer on the unit area of the main roof fault block above a coal pillar during mining, MPa; $Q$ ' is the load transmitted to the fault block of the main roof above the fault coal pillar by the main roof rotating fault block in the goaf, $\mathrm{MN} / \mathrm{m} ; B$ is the width of the coal pillar, $\mathrm{m} ; D$ is the width of the mining roadway near the fault plane, $\mathrm{m}$; and $\alpha$ is the inclination angle of the fault.

According to the mechanical equilibrium analysis of hinged rock block formation, during mining under normal faults, large fault plane tilt angles can cause main roof fault blocks to form articulations on the fault planes, and the horizontal pressure and vertical load on the main roof of the goaf can be transmitted to the hanging wall (Pan et al. 1998). At the same time, the conditions of rock block formations must be judged by the width of the fault zone and the strength of the rock strata of the hanging wall and footwall of the fault zone. If the width of the fault zone is large or the strength of the rock strata of the main roof is low, the rotation of small rock blocks in the fault zone and the easily damaged main roof rock mass will greatly reduce the probability of forming a mechanical equilibrium structure. The formation of a hinged point of a stable fault block is simultaneously controlled by three conditions: a large fault dip $\left(45^{\circ}-52^{\circ}\right)$, a hard main roof fault block, and a thin fault zone (Dai and Jiang 2016). According to Voussoir beam theory, regardless of whether the load in the goaf is transmitted to the hanging wall, the load strengths of the coal pillars can be calculated by Eqs. (1) and (2), respectively (Qian et al. 1994).

The goaf transfers the load to the hanging wall:

$$
\begin{aligned}
& q_{\mathrm{d}}=\frac{\frac{3(1-K) q L}{2}+\gamma_{\mathrm{z}} h_{\mathrm{z}}\left(\frac{h_{\mathrm{z}} \tan \alpha}{2}+h_{\mathrm{d}} c \tan \alpha+B+D\right)+\gamma_{\mathrm{d}} h_{\mathrm{d}}\left(\frac{h_{\mathrm{d}} \tan \alpha}{2}+B+D\right)}{B} \\
& +\gamma H
\end{aligned}
$$

where, $q_{\mathrm{d}}$ is the upper load strength, MPa; $K$ is the fault pressure transfer coefficient; $\gamma_{z}$ is the bulk density of the rock strata of the immediate roof, $\mathrm{kN} / \mathrm{m}^{3} ; h_{\mathrm{z}}$ is the thickness of the rock strata of the immediate roof, $\mathrm{m} ; h_{\mathrm{d}}$ is the thickness of the roof coal, $\mathrm{m} ; \gamma$ is the average bulk density of the overlying load layer and the current layer on the unit area of the main roof fault block above a coal pillar during mining, $\mathrm{kN} / \mathrm{m}^{3}$; and $H$ is the total thickness of the overlying load layer and the current layer on the unit area of the main roof fault block above a coal pillar during mining, $\mathrm{m}$.

The goaf does not transfer the load to the hanging wall:

$$
q_{\mathrm{d}}=\frac{\frac{3 q L}{2}+\gamma_{\mathrm{z}} h_{\mathrm{z}}\left(B+D-h_{\mathrm{d}} c \tan \alpha-\frac{h_{\mathrm{z}} \tan \alpha}{2}\right)+\gamma_{\mathrm{d}} h_{\mathrm{d}}\left(B+D-\frac{h_{\mathrm{d}} c \tan \alpha}{2}\right)}{B}+\gamma H
$$

When the footwall mining meets the conditions necessary for rock block hinge formation, part of the load will be transferred to the fault hanging wall through the articulated point, and Eq. (1) can be used to calculate the load strength of a coal pillar. When the footwall mining does not meet the conditions necessary for rock block hinge formation, the rock blocks above the coal pillar cannot form a selfbalanced support point, and the main roof fault block will slip along the fault plane under the load. At this time, the load cannot be transmitted through the fault plane to the hanging wall, and the load on the coal pillar is the sum of the loads of the whole main roof block structure and the immediate roof, which can be calculated via Eq. (2). In this case, to achieve a higher mining recovery, the width $(B)$ of the coal pillar is designed to be narrower. The load on the coal pillar cannot be relieved or transferred, which causes either slow failure or rock fracture in the mining roadway. Therefore, leaving coal pillars of reasonable size is particularly important. In the 15101 working face of a mining area of the Baiyangling Coal Mine, Shanxi, the coal seam was truncated by the F3 normal fault at a $60^{\circ}$ inclination. The direct and main roofs are mainly mudstones, and hard main roof fault blocks and balanced hinges are less likely to form. According to the foregoing analysis, the pressure on the coal pillar between the goaf and the fault will increase under the condition that the main roof load cannot be transmitted. Based on the actual situation of the working face determined in subsequent research, a similar test model is established. Pressure sensors and speckle tests are used to collect the stress and deformation information of the fault plane, surrounding rocks and coal pillars near the fault, analyse the fault activation and surrounding rock instability law, and determine the optimal coal pillar width.

\section{Similar model test design}

\subsection{Similar test prototype}

The 15101 working face in the mining area of the Baiyangling Coal Mine has a mining depth of $500 \mathrm{~m}$ and an average coal thickness of $4 \mathrm{~m}$. The inclination of the coal seam is approximately $0^{\circ}$, and the coal seam structure is simple and in an essentially stable state. The main roof is 6-m-thick fine-grained sandstone, and the immediate roof is 16-m-thick sandy mudstone, as shown in Table 1 . The 
physical and mechanical parameters of the rocks and coal seams are shown in Table 2. A normal fault with an inclination angle of $60^{\circ}$ cuts the coal seam, and the fault throw is $0.4 \mathrm{~m}$. To maximize the mining rate, a minimum coal pillar width needs to be preset to ensure the safe development of mining activities near the fault plane. The mining roadway design of the 15101 working face is approximately rectangular, with a width of $5.5 \mathrm{~m}$, a height of $4.0 \mathrm{~m}$, and a sectional area of $20.9 \mathrm{~m}^{2}$.

\subsection{Physical aspects of the similar test model}

\subsubsection{Similar test simulation scheme}

Considering the actual situation of the working face, for a coal seam under a normal fault at an inclination angle of $60^{\circ}$, the failure and instability characteristics of the fault, coal pillar and surrounding rock of the mining roadway are simulated for the values of coal pillar width $B$ of $20 \mathrm{~m}$, $15 \mathrm{~m}, 10 \mathrm{~m}, 5 \mathrm{~m}$, and $0 \mathrm{~m}$. This test uses a 2D similar simulation test stand. The length of the model frame is $2 \mathrm{~m}$, and the width is $0.24 \mathrm{~m}$. The height can be freely adjusted according to the size of the model. The template for layered paving is $2 \mathrm{~m}$ in length and $0.1 \mathrm{~m}$ in height. The two ends are fixed with clips. A transparent tempered glass plate with a length of $2 \mathrm{~m}$, a width of $1.5 \mathrm{~m}$ and a thickness of $5 \mathrm{~mm}$ is used to restrain the loose sand loaded on the upper part of the model. The model frame is suitable for various similar model tests and is simple and convenient to assemble and disassemble.

\subsubsection{Determination of proportional similarity}

The model is based on geometric similarity, strength similarity, and physical process similarity to actual engineering. Quartz sand is used as an aggregate in the similar model, and caulking gypsum and dolomitic lime are used as cementing materials. The boundaries between layers of rock strata and other weak surfaces are created by mica sheets. The similarity ratio of the similar model selected for each rock stratum are as follows: the geometric similarity ratio, displacement ratio: $C_{1}=C_{\delta}=50$, similarity ratios of the bulk density, Poisson's ratio, strain and internal friction angle of the coal seam and various rock strata: $C_{\gamma}=C_{\mu-}$ $=C_{\varepsilon}=C_{\phi}=1$, and similarity ratio of the compressive strengths of the coal seam and various rock strata: $C_{\mathrm{p}}$ $=C_{\mathrm{R}}=500$. After many trials of matching ratios of similar materials in the initial stage of the test, the material matching ratios that satisfy the test are determined. See Table 3 for details.

The water-cement ratio is $1: 1$. According to the geometric parameters and the physical and mechanical indexes of the original rock combined with the selected geometric similarity ratio and strength similarity ratio, the amounts of various materials used in each rock stratum in the model and the thickness of the model layers are calculated (Singh and Singh 1999). The composition parameters of the specific model are shown in Table 4.

\subsubsection{Monitoring method of the similar model test}

The testing device adopts a YJZA-32 intelligent digital stress acquisition instrument and digital speckle system to collect the force and deformation information of the test model. The accuracy of the resistance measurement method using the YJZA-32 intelligent digital stress acquisition instrument is $\pm 0.1 \%$ of the measurement value, the acquisition rate is $1 \mathrm{~s}$ per point, and the sensitivity coefficient is $0.001-999.999$. The acquisition instrument is used in synchronous matching mode with multiple button-type pressure sensors. Each button-type pressure sensor has a diameter of $28 \mathrm{~mm}$ and a thickness of $10 \mathrm{~mm}$.

Deformation information collection technology based on the optical principle has the advantage of non-contact continuous monitoring (Singh et al. 1997). The digital speckle acquisition system is mainly composed of a charge-coupled device (CCD) camera, stents and a computer processing system. The digital speckle correlation method (DSCM) can compare and process the high-definition target image information collected by the CCD with the initial image information and then calculate the

Table 1 Coal roof and floor conditions

\begin{tabular}{|c|c|c|c|}
\hline $\begin{array}{l}\text { Roof or floor } \\
\text { name }\end{array}$ & Lithology & $\begin{array}{l}\text { Thickness } \\
(\mathrm{m})\end{array}$ & Characteristics \\
\hline Main roof & $\begin{array}{l}\text { Fine-grained } \\
\text { sandstone }\end{array}$ & 6 & $\begin{array}{l}\text { Grey and thickly bedded. The lower particle size is finer, representing both siltstone and } \\
\text { fine sandstone }\end{array}$ \\
\hline Immediate roof & Sandy mudstone & 16 & Grey to grey-black and thickly bedded \\
\hline Immediate floor & Mudstone & 9 & Grey to black. The upper part is massive mudstone, and the lower part is flaggy mudstone \\
\hline Main floor & $\begin{array}{l}\text { Fine-grained } \\
\text { sandstone }\end{array}$ & 5 & $\begin{array}{l}\text { Grey to off-white, medium-grained sandstone. The particle size of the upper area is finer } \\
\text { siltstone }\end{array}$ \\
\hline
\end{tabular}


Table 2 Mechanical properties of the coal strata

\begin{tabular}{llllllll}
\hline Lithology & $\begin{array}{l}\text { Elastic } \\
\text { modulus } \\
E(\mathrm{GPa})\end{array}$ & $\begin{array}{l}\text { Poisson's } \\
\text { ratio } \\
\mu\end{array}$ & $\begin{array}{l}\text { Density } \rho \\
\left(10^{3}\right. \\
\left.\mathrm{kg} / \mathrm{m}^{3}\right)\end{array}$ & $\begin{array}{l}\text { Cohesion } \\
(\mathrm{MPa})\end{array}$ & $\begin{array}{l}\text { Internal friction angle } \varphi \\
\left(^{\circ}\right)\end{array}$ & $\begin{array}{l}\text { Tensile } \\
\text { strength } \\
R_{\mathrm{L}}(\mathrm{MPa})\end{array}$ & $\begin{array}{l}\text { Compressive } \\
\text { strength } \\
R_{\mathrm{C}}(\mathrm{MPa})\end{array}$ \\
\hline $\begin{array}{l}\text { Fine-grained } \\
\text { sandstone }\end{array}$ & 1.65 & 0.23 & 2.48 & 2.64 & 41.47 & 1.16 & 26.96 \\
$\begin{array}{l}\text { Mudstone } \\
\text { Coal seam }\end{array}$ & 1.12 & 0.22 & 2.28 & 1.27 & 42 & 0.79 & 0.36 \\
$\begin{array}{l}\text { Sandy mudstone } \\
\text { Fine-grained }\end{array}$ & 0.54 & 0.21 & 1.75 & 0.85 & 37.5 & 0.95 & 21.7 \\
$\quad$ sandstone & 1.27 & 0.23 & 2.35 & 1.62 & 38.6 & 1.31 & 33.62 \\
\hline
\end{tabular}

Table 3 Proportion of similar materials for coal and rock

\begin{tabular}{lll}
\hline Roof and floor name & Lithology & Quartz sand: Lime: Gypsum \\
\hline Main roof & Fine-grained sandstone & $6: 0.7: 0.3$ \\
Immediate roof & Sandy mudstone & $7: 0.7: 0.3$ \\
Coal seam & Coal & $10: 0.7: 0.3$ \\
Immediate floor & Mudstone & $8: 0.7: 0.3$ \\
Main floor & Fine-grained sandstone & $6: 0.7: 0.3$ \\
\hline
\end{tabular}

Table 4 The thicknesses, strength indexes and model material ratios of the similar model of the rock strata used for testing

\begin{tabular}{|c|c|c|c|c|c|c|c|c|}
\hline Position & $\begin{array}{l}\text { Original rock } \\
\text { thickness }(\mathrm{m})\end{array}$ & $\begin{array}{l}\text { Model } \\
\text { thickness } \\
(\mathrm{cm})\end{array}$ & $\begin{array}{l}\text { Original rock } \\
\text { compressive strength } \\
\text { (MPa) }\end{array}$ & $\begin{array}{l}\text { Model } \\
\text { compressive } \\
\text { strength } \\
(\mathrm{MPa})\end{array}$ & $\begin{array}{l}\text { Quantity of } \\
\text { quartz sand } \\
(\mathrm{kg})\end{array}$ & $\begin{array}{l}\text { Quantity of } \\
\text { lime (kg) }\end{array}$ & $\begin{array}{l}\text { Quantity of } \\
\text { gypsum (kg) }\end{array}$ & $\begin{array}{l}\text { Quantity of } \\
\text { water }(\mathrm{kg})\end{array}$ \\
\hline Main roof & 6 & 12 & 29.96 & 0.06 & 103 & 11.9 & 5.1 & 15 \\
\hline $\begin{array}{l}\text { Immediate } \\
\text { roof }\end{array}$ & 16 & 32 & 21.7 & 0.04 & 280 & 28 & 12 & 35 \\
\hline Coal seam & 4 & 8 & 7.2 & 0.0144 & 73 & 5.1 & 1.9 & 9 \\
\hline $\begin{array}{l}\text { Immediate } \\
\text { floor }\end{array}$ & 9 & 18 & 17.0 & 0.035 & 155.6 & 13.6 & 5.8 & 20 \\
\hline Main floor & 5 & 10 & 33.62 & 0.066 & 85.7 & 10.1 & 4.2 & 12.5 \\
\hline
\end{tabular}

displacement and strain field of the target image. DSCM obtains the observation surface deformation process by tracking and identifying the trajectory of the digital speckle points on the surface of the test piece during the loading process. As shown in Fig. 2, the first picture captured by DSCM is taken as the reference image $I_{0}$, and a series of images $I_{\mathrm{n}}$ captured in the subsequent loading yields the deformed image. If point $\mathrm{A}$ in the reference image $\mathrm{I} 0$ is taken as the analysis object, then the target image at a corresponding time in the series of deformed images can be extracted, and the point $\mathrm{B}$ characteristic speckle pattern matching the point A characteristic speckle pattern can be determined. The difference in deformation between points
$\mathrm{A}$ and $\mathrm{B}$ is the deformation value at point $\mathrm{A}$. The matching degree of $f$ and $g$ is characterized by the correlation function $C$, and $C$ indicates the best match when it takes the maximum value, see Eq. (3) for details (Ma et al. 2002; Pan et al. 1998).

$C=\frac{\sum\left\{[f(x, y)-\bar{f}]\left[g\left(x^{\prime}, y^{\prime}\right)-\bar{g}\right]\right\}}{\sqrt{[f(x, y)-\bar{f}]^{2}} \sqrt{\left[g\left(x^{\prime}, y^{\prime}\right)-\bar{g}\right]^{2}}}$

In the formula, $f(x, y)$ and $g\left(x^{\prime}, y^{\prime}\right)$ are the grey-scale function of a small area, and $f$ and $\bar{g}$ are the average values of $f(x, y)$ and $g\left(x^{\prime}, y^{\prime}\right)$, respectively. 


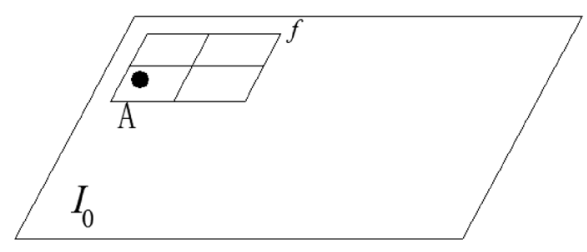

Before deformation
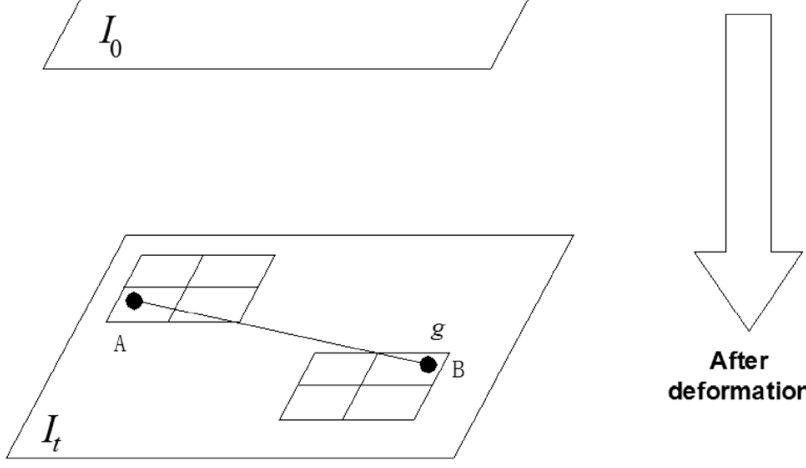

deformation

Fig. 2 Schematic of the test structure

The resolution of the CCD camera is 1630 pixels $\times 1224$ pixels. The surface of the model needs to be manually sprayed with a speckle field. The CCD orientation is corrected to capture the entire area of the end face of the specimen, and the frequency of the image acquisition is 8 frames/s. The method of synchronously placing a ruler on the surface of the model is used to calibrate the pixels and the size. The calibration resolution of the speckle is $0.15 \mathrm{~mm} /$ pixel. After calibration, the model and speckle acquisition equipment cannot be moved.

The pressure sensor layout along the fault, rock strata, and coal in the similar material model is shown in Fig. 3. According to the similarity ratio, the monitoring point positions are described according to the actual project size. Specifically, T4, T5, T6, T7, and T3 are located at horizontal distances from the fault of $-1 \mathrm{~m}$ (hanging wall), $0 \mathrm{~m}$ (footwall), $2 \mathrm{~m}, 4 \mathrm{~m}$ and $6 \mathrm{~m}$; T3, T4, T5, T6 and T7 are at the same level as the roof; $\mathrm{T} 1$ and $\mathrm{T} 2$ are at the same level as the floor, with $\mathrm{T} 1$ in the hanging wall and $\mathrm{T} 2$ vertically below T3; T8 is located in the immediate roof of the footwall, $8 \mathrm{~m}$ from the main roof; and T9 is located in the main roof of the footwall, $3 \mathrm{~m}$ from the immediate roof. Subsequent correlation analysis will convert the model

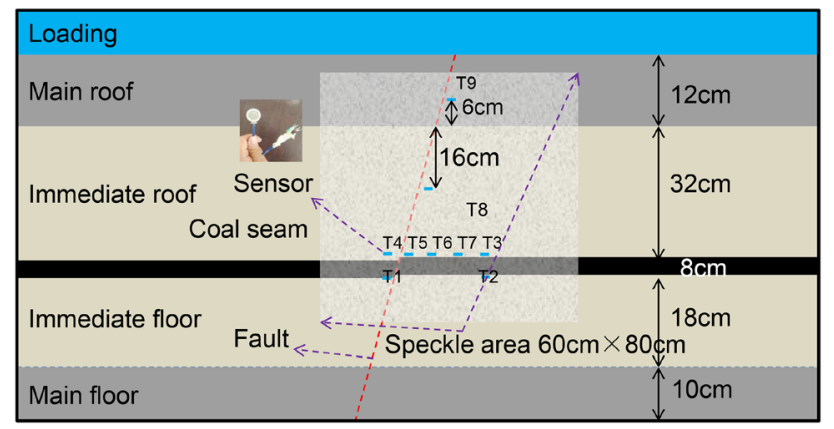

Fig. 3 Size of the similar model and pressure sensor arrangement indexes into actual engineering indexes for similarity ratiobased analysis.

\subsection{Test process}

\subsubsection{Model-making process}

The model-making process is shown in Fig. 4. According to the model material ratios in Table 4 , for each rock stratum, the quartz sand, lime, and gypsum are weighed and mixed uniformly. The corresponding proportion of water is added, and the slurry is stirred for 3 to 4 min until homogenous. First, the 2D similar model framework is set up as a template step by step, the similar material corresponding to the rock stratum is added, and compaction is performed layer by layer. While creating the model, the position of the fault and the corresponding pressure sensor are calibrated to a preset layer. Mica sheets are embedded into a $5 \mathrm{~mm}$ gap reserved for the simulated fault, and the corresponding pressure sensor is embedded at the designed position.

The model form is removed after 2 days, and the area of the artificial speckle field is 5 times the mining height. The speckle field is $80 \mathrm{~cm}$ high and $60 \mathrm{~cm}$ wide. The speckle points are fixed with a pin so that the speckles do not overlap and can deform independently (Ma et al. 2002). The loading of this test model is performed via the packing static loading of quartz sand. According to the actual burial depth, the height of the quartz sand is $52 \mathrm{~cm}$. Six templates
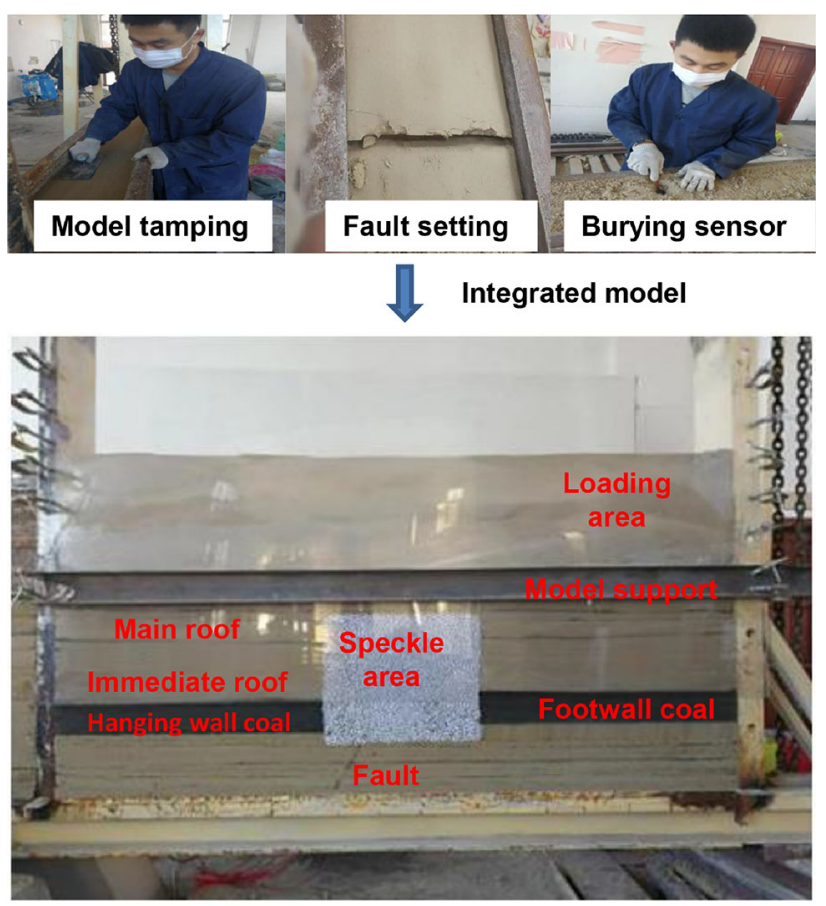

Fig. 4 Similar model production process 
are added behind the model. A transparent tempered glass plate is placed in front of the model. The lowest end of the glass plate is flush with the roof of the coal seam. At the roof layer of the strata, a template and fixtures are used to fix the tempered glass plate. The fixtures are used to directly clamp the two edges of the model frame to prevent the tempered glass plate from falling off and the quartz sand heaped on the roof from leaking.

\subsubsection{Information collection process}

First, the pressure box wire is connected to a YJZA-32 intelligent digital strain gauge. The device is turned on to adjust the initial pressure box strain indicator to 0 . Then, the strain gauge is connected to the computer to record the pressure change subjected by the pressure box, which is processed by the strain gauge and transmitted to the computer for data collection.

In the digital speckle system, the camera is connected to the crate and placed $1.5 \mathrm{~m}$ from the model. Because the area of the artificial speckle field is large, the height of the triangular frame is adjusted to keep the camera perpendicular to the speckle field. The vertical height of the camera is $68 \mathrm{~cm}$, as shown in Fig. 5. The aperture of the camera is adjusted until the speckle field is clearly displayed on the computer screen.

\section{Analysis of the test results}

\subsection{Displacement field characteristics of the surrounding rock during mining}

After processing the collected digital speckle images by MATLAB software, the vertical displacement field of the surrounding rock near the fault is obtained, considering the different coal pillar widths, as shown in Fig. 6. As shown in Fig. 6a, the model exhibits no obvious displacement, and the surrounding rock is in the initial state at this time. As shown in Fig. 6b, when the coal pillar width is $20 \mathrm{~m}$, the surrounding rock near the fault experiences a maximum vertical displacement of $0.5 \mathrm{~cm}$. The isoline areas between $0.25-0.5 \mathrm{~cm}$ are scattered and are mainly distributed in the footwall of the fault. As shown in Fig. 6c, when the coal pillar width is $15 \mathrm{~m}$, the maximum vertical displacement of the surrounding rock near the fault increases to $1.5 \mathrm{~cm}$, and the local displacement of the coal pillar is only $0.5 \mathrm{~cm}$. The isoline areas between 0.5 and $1.5 \mathrm{~cm}$ are concentrated and distributed near the fault. As shown in Fig. $6 \mathrm{~d}$, when the coal pillar width is $10 \mathrm{~m}$, the maximum vertical displacement of the coal pillars between the faults reaches approximately $25 \mathrm{~cm}$. The $50 \mathrm{~cm}$ displacement value of the mining roadway forms a closed isoline area. The immediate roof has a vertical displacement of $50 \mathrm{~cm}$, and it starts to collapse near the side of the goaf, but the displacement of the main roof changes only slightly. As shown in Fig. 6e, when the coal pillar is $5 \mathrm{~m}$, the isoline area with a vertical displacement of more than $50 \mathrm{~cm}$ is distributed on the side of the free face of the coal pillar. In this case, the roadways begin to exhibit rib spalling, and the coals of the coal pillars outburst near the free surface. At this time, the maximum displacement of the surrounding rock of the mining roadway is $200 \mathrm{~cm}$, and the immediate roof of the corresponding position has collapsed. The surrounding rock of the mining roadway has also collapsed. The displacement of the overlying main roof of the roadway also reaches a displacement of $50 \mathrm{~cm}$, and undergoes tension cracking failure, but the rock mass of the hanging wall on the structural surface does not exhibit significant displacement. As shown in Fig. 6f, when no coal pillars are
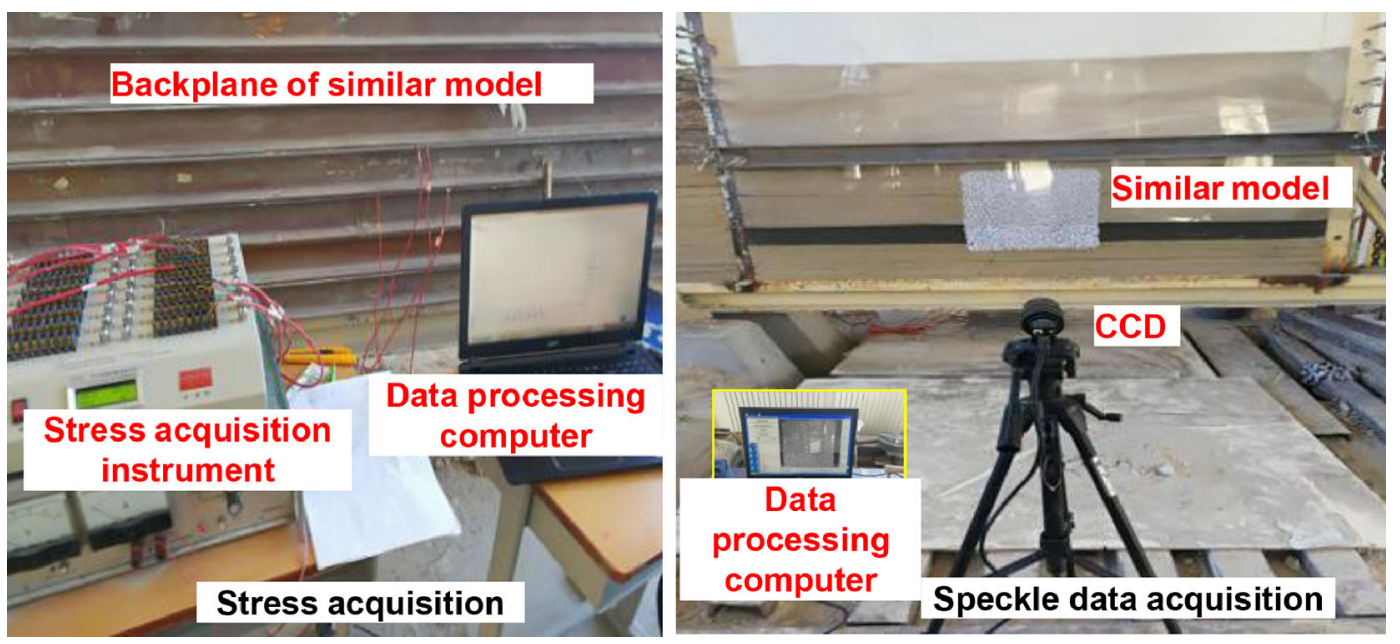

Fig. 5 Stress and deformation collection 

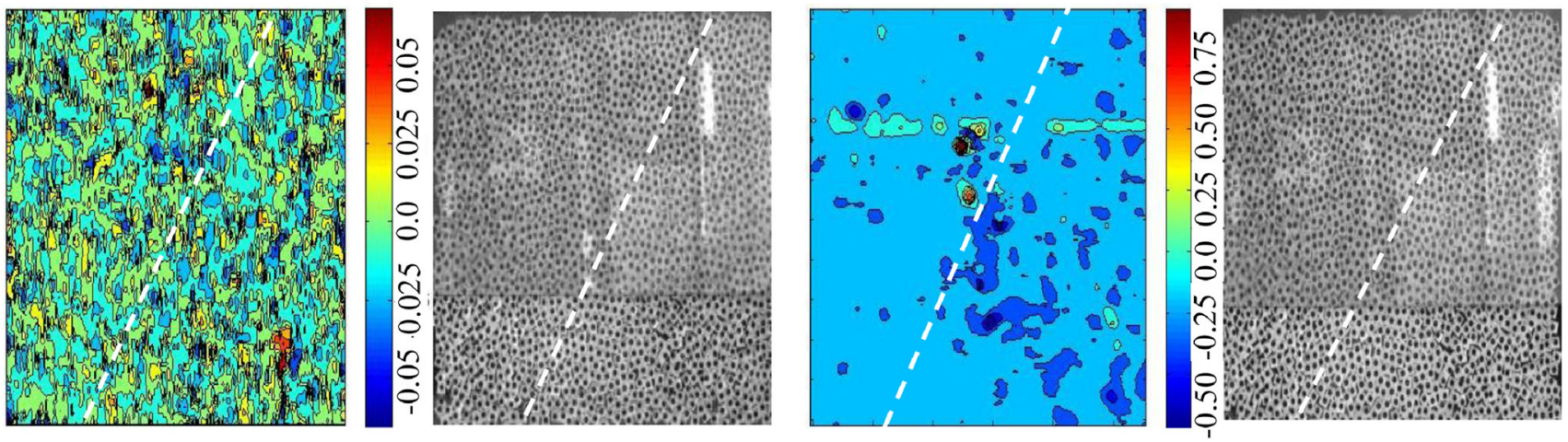

(a) Initial
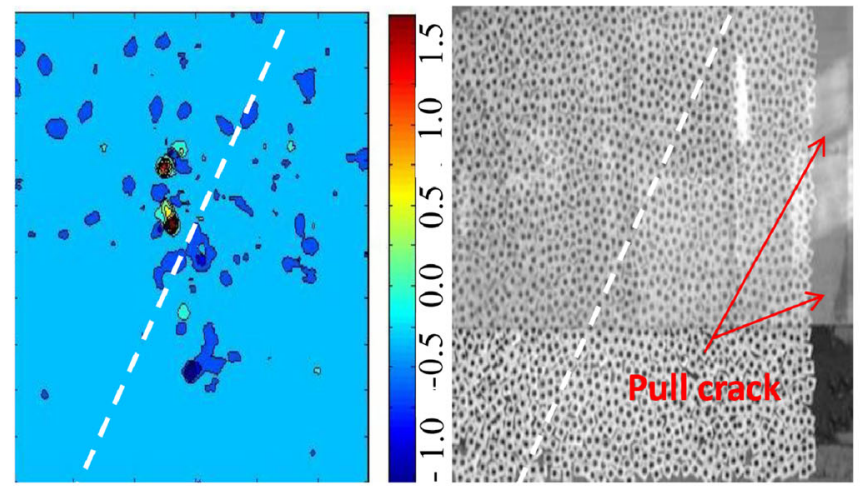

(b) $20 \mathrm{~m}$

\section{(c) $15 \mathrm{~m}$}
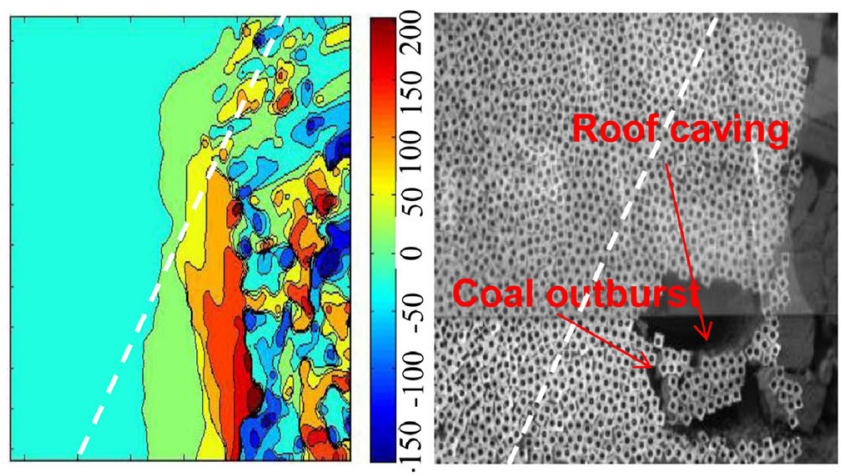

(e) $5 \mathrm{~m}$
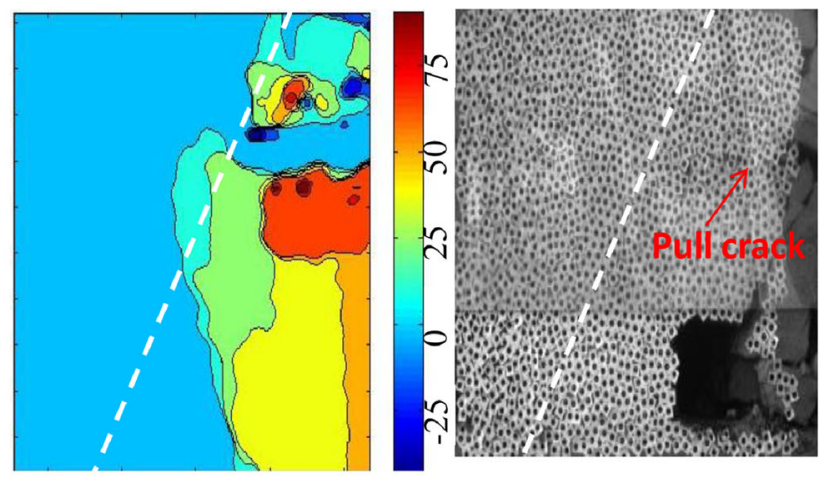

(d) $10 \mathrm{~m}$
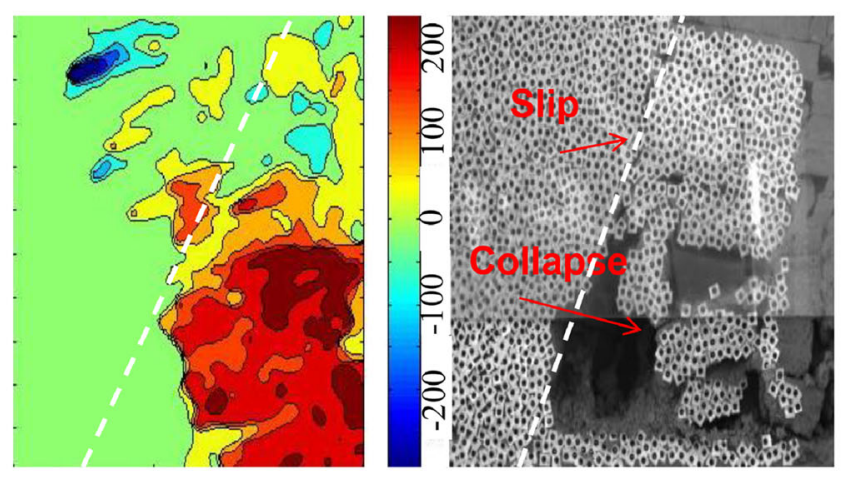

(f) $0 \mathrm{~m}$

Fig. 6 Vertical displacement of the surrounding rocks near faults with different pillar widths

left, the immediate roof of the roadway exhibits general demolition failure. The main roof slips along the fault plane, and an isoline distribution area of $25 \mathrm{~cm}$ occurs in the local area of the immediate roof, which is the main roof of the coal seam hanging wall. Local rock mass shedding also occurs. These findings suggest that under the condition in which the footwall does not form a balanced articulation, during the sliding process of the roof caving, part of the load disturbance effect is still transmitted to the hanging wall through the friction along the fault, causing the hanging wall to displace and partially collapse.

The relationship between the width of the coal pillar and the maximum vertical displacement of the surrounding rock near the fault is drawn, as shown in Fig. 7. When the width $B$ of the coal pillar is $10 \mathrm{~m}<B<20 \mathrm{~m}$, the vertical displacement of the surrounding rock near the fault 
increases slightly as the width of the coal pillar narrows, but it is basically in a stable state. When the width of the coal pillar is less than $10 \mathrm{~m}$, the slope of the vertical displacement curve increases significantly as the width of the coal pillar narrows. The narrower coal pillar bears a higher surrounding rock pressure and undergoes considerable compression. Excessive deformation of the coal pillar further induces the vertical displacement of the surrounding rock near the fault. When the width of the coal pillar is $5 \mathrm{~m}$, the maximum vertical displacement reaches $200 \mathrm{~cm}$, and the surrounding rock of the roadway collapses.

\subsection{The strain field characteristics in the fault plane and the surrounding rocks near coal pillars}

By using the digital speckle system to monitor the deformation of the surrounding rock of the roadway, the change in the vertical strain field in the surrounding rock of the roadway is obtained, as shown in Fig. 8. The state of the surrounding rock near the fault before mining is shown in Fig. 8a. The maximum vertical strain in the vertical direction does not exceed $3 \times 10^{-4}$, the strain distribution is irregular, and the model is in a stable initial state. As shown in Fig. 8b, when the coal pillar width is $20 \mathrm{~m}$, the surrounding rock around the fault sporadically exhibits areas of $2 \times 10^{-3}$ strain concentration, and the maximum strain among the hanging wall and footwall positions of the immediate roof fault is $8 \times 10^{-3}$, which indicates that the mining at this time has a slight influence on the surrounding rock near the fault. As shown in Fig. 8c, when the coal pillar width is $15 \mathrm{~m}$, the maximum tensile strain near the fault is $12 \times 10^{-3}$, and the compressive strain is $8 \times 10^{-3}$. Tensile and compressive strain concentrations

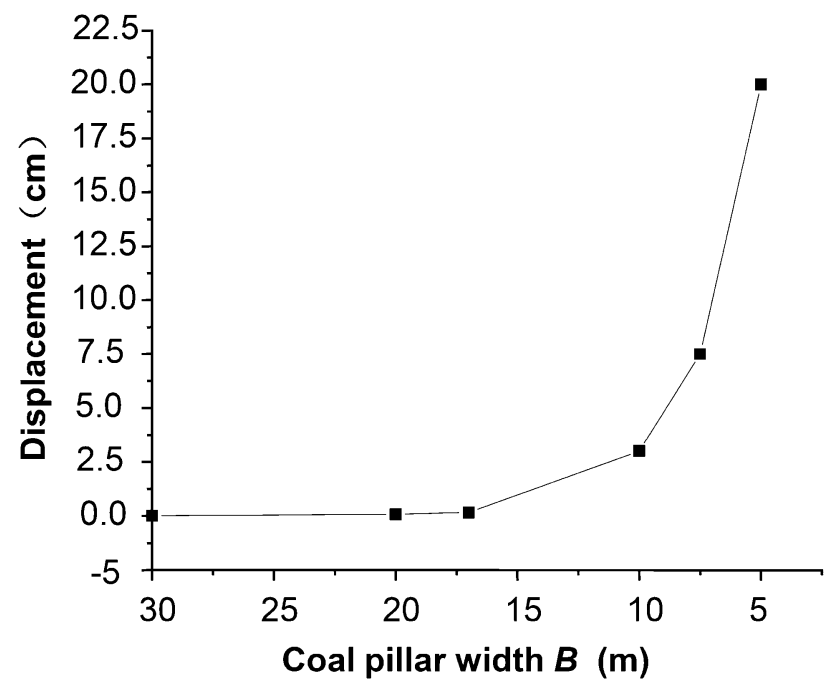

Fig. 7 Relationship between the coal pillar width and maximum vertical displacement

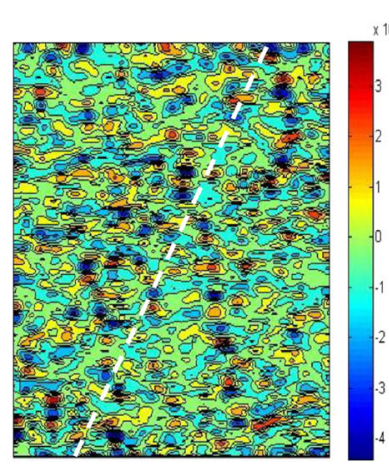

(a) Initial

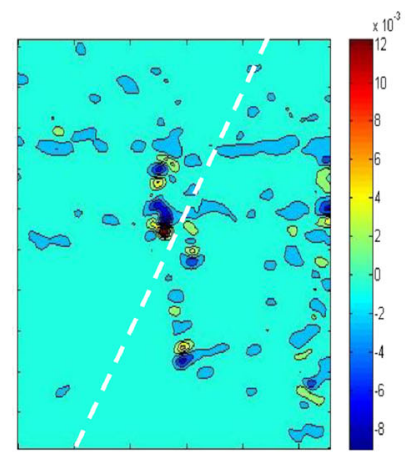

(c) $15 \mathrm{~m}$

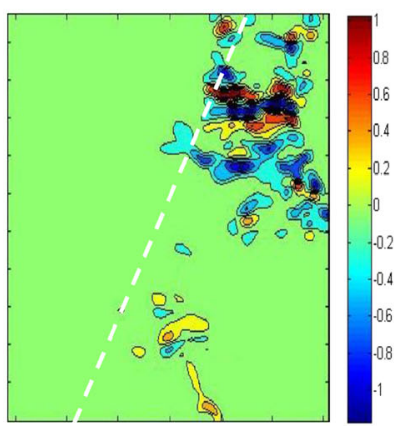

(e) $5 \mathrm{~m}$

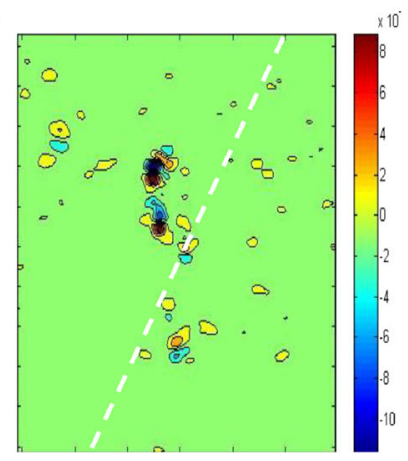

(b) $20 \mathrm{~m}$

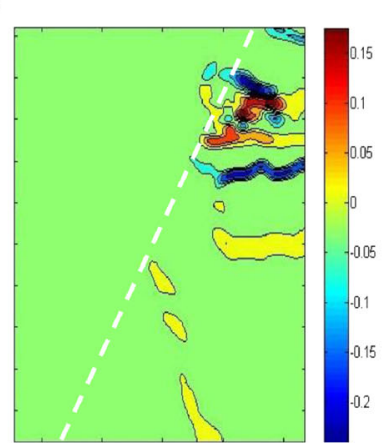

(d) $10 \mathrm{~m}$

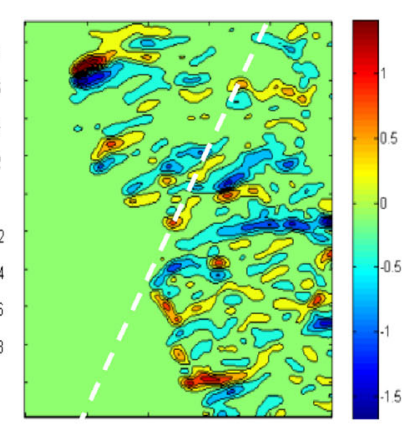

(f) $0 \mathrm{~m}$
Fig. 8 Vertical strain of the surrounding rock at different coal pillar widths

have a tendency to appear in pairs. The other strain concentration areas of $\pm 2 \times 10^{-3}$ show a sporadic distribution in the coal pillar, and most are compressive strains $\left(-2 \times 10^{-3}\right)$. Therefore, although the roof surrounding rock does not form stable articulation, the friction between the main roof relying on the rock mass before the roof collapsed in the goaf area still transmits part of the horizontal extrusion pressure to the rock mass around the fault, resulting in a compressive strain area. After the roof falls, most of the strain areas that were originally compressive are converted into tensile strain areas. As shown in Fig. 8d, when the coal pillar width is $10 \mathrm{~m}$, the roof of the coal 
seam in the footwall of the fault exhibits a strain concentration zone. From the floor to the roof, tensile strain, compressive strain, and tensile strain concentration areas form. The corresponding maximum strain magnitudes are $0.025,-0.2$ and 0.1 . Therefore, the local surrounding rock in the roof of the mining roadway in the fault footwall forms a very large deformation area. At this time, no stable articulation is formed to transfer the load to the hanging wall of the fault. The fault shields the load transfer from the footwall, and the hanging wall surrounding rock is not considerably affected. A shear and tension crack zone with a strain of 0.05 perpendicular to the fault zone forms inside the coal pillar, indicating that the coal pillar near the fault plane is no longer constrained by the parent rock, and the coal pillar tends to be pressure-fed under the action of excessively high pressure. As shown in Fig. 8e, when the coal pillar width is $5 \mathrm{~m}$, the large strain concentration area in the surrounding rock of the roof is replaced by a nonuniformly distributed deformation area with a strain of \pm 1 . When the blocky rock mass is not articulated, the position of the corresponding surrounding rock of the roof collapses. Sufficient support strength must be provided in real coal resource mining so that the surrounding rock between the fault floor and the roof of the mining roadway remains stable. To further analyse the fault shielding and load transfer law, we continue to observe the strain field of the surrounding rock near the fault without coal pillars, as shown in Fig. 8f. Plastic zones with strains of $\pm 0.5- \pm 1$ appear in pairs in the hanging wall and footwall of the fault, and the distribution of these zones is relatively disordered. When the model collapses, under the support of the collapsed rock mass, the roof of the upper fault does not collapse, so that the surrounding rock exhibits a stable area. If mining is needed to reach the fault plane, it is necessary to make full use of the supporting effect of the collapsed rock body while also utilizing the strong support effect, but the support timing needs further research.

The relationship between the coal pillar width and the maximum vertical strain in the vertical direction of the surrounding rock near the fault is drawn, as shown in Fig. 9. When the coal pillar width is between 10 and $20 \mathrm{~m}$, as the coal pillar width becomes narrower, the maximum vertical strain curve changes gently. The steep increase in the curve starts when the width of the coal pillar is $10 \mathrm{~m}$. Additionally, the slope of the increasing maximum vertical strain is large when the width of the leaving coal pillar is $5 \mathrm{~m}$, and the disturbance of each mining step may cause instability in the surrounding rock, coal pillar and mining roadway. When no coal pillar is left, the surrounding rock exhibits fault activation instability without sufficient support.

Synthesizing the above analysis results, when the width of the coal pillar is larger than $10 \mathrm{~m}$, the surrounding rocks

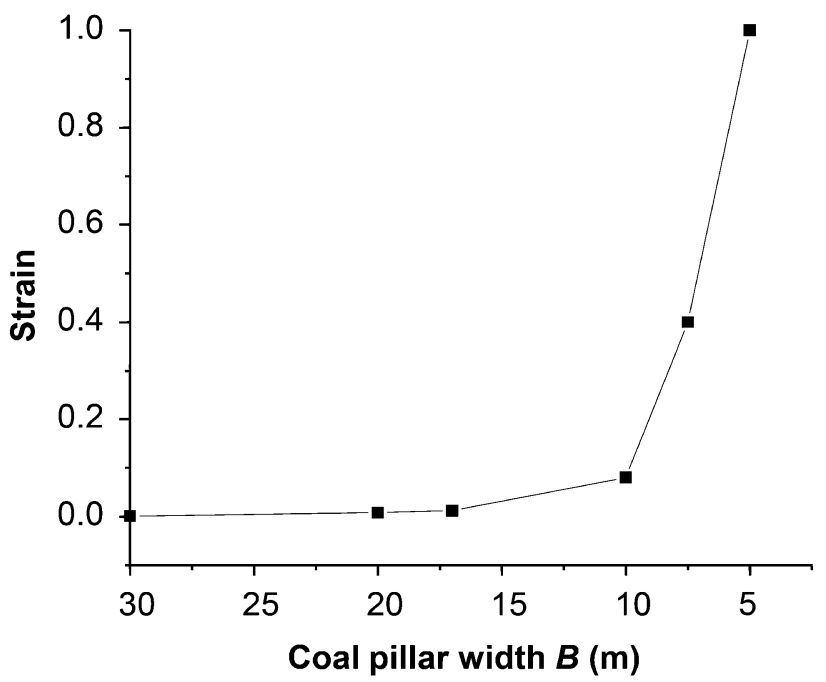

Fig. 9 Relationship between the coal pillar width and maximum vertical strain

near the fault and the surrounding rocks of the mining roadway are in a stable stage. When the width of the coal pillar is less than $10 \mathrm{~m}$, the surrounding rock of the roadway enters an unstable stage. When the width of the coal pillar is less than $5 \mathrm{~m}$, if the coal pillar and the roof are not sufficiently supported, the roof will collapse, the coal pillar will undergo coal outburst, the fault will slip, and the surrounding rocks and mining roadways near the fault will be unstable. Considering comprehensive factors such as support, it is too conservative to directly choose a coal pillar width of $10 \mathrm{~m}$. It is also necessary to determine the most reasonable coal pillar width between 5 and $10 \mathrm{~m}$ through vertical stress (stress) analysis.

\subsection{Stress characteristics of the surrounding rock near the fault}

Displacement and strain monitoring is used to optimize the coal pillar width. The stress sensors can achieve synchronous and continuous data collection during the model mining process. The optimal coal pillar width can be determined by further analysis of the stress. The monitoring point location in the model is converted into the actual position according to the geometric similarity ratio, as shown in Fig. 10.

\subsubsection{Analysis of the change in the surrounding rock stress in the roadway roof}

According to the data measured by the pressure sensor, the corresponding relation between the stress change increment and the width of the coal pillar at different positions of the roof is obtained, as shown in Fig. 11. Compared with the initial stress state of the model, when the width of the 


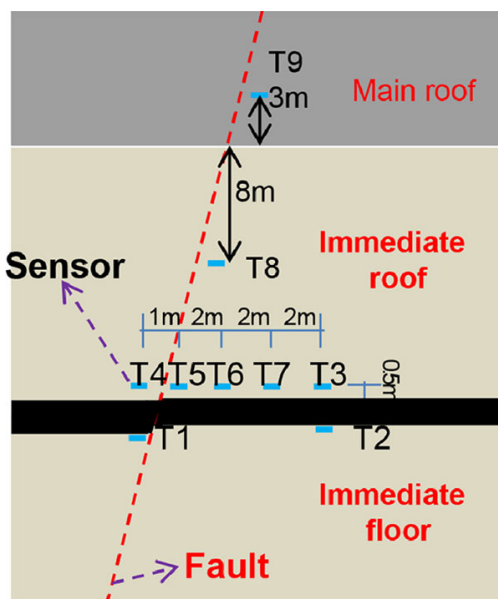

Fig. 10 Monitoring point locations in the model

coal pillar is no less than $17 \mathrm{~m}$, and the stress of the coal pillar is basically unchanged. When the width of the coal pillar is $10 \mathrm{~m}$, the stress at T4 remains basically unchanged, and the fault acts to shield the stress. When the coal pillar width is $10 \mathrm{~m}$, the stress at T5 located near the fault in the footwall is reduced by $1.5 \mathrm{MPa}$, and the stress increment that is generated at the hanging wall positions of $\mathrm{T} 6$ and $\mathrm{T} 7$ is $0.25 \mathrm{MPa}$. Thus, the main roof collapses, and the pressure of the surrounding rock starts to transfer to the coal pillar. The rock mass near the fault plane is divided, and the surrounding rock pressure cannot be transmitted. The vertical surrounding rock pressure at T5 begins to decrease. When the width of the coal pillar is between 5 and $10 \mathrm{~m}$, the stress at the roof on the left side of the fault hanging wall $\mathrm{T} 4$ is increased by only $0.05 \mathrm{MPa}$. The stress at T5 begins to decrease abruptly when the width of the coal pillar is $9 \mathrm{~m}$, and at the same time, roof positions $\mathrm{T} 6$

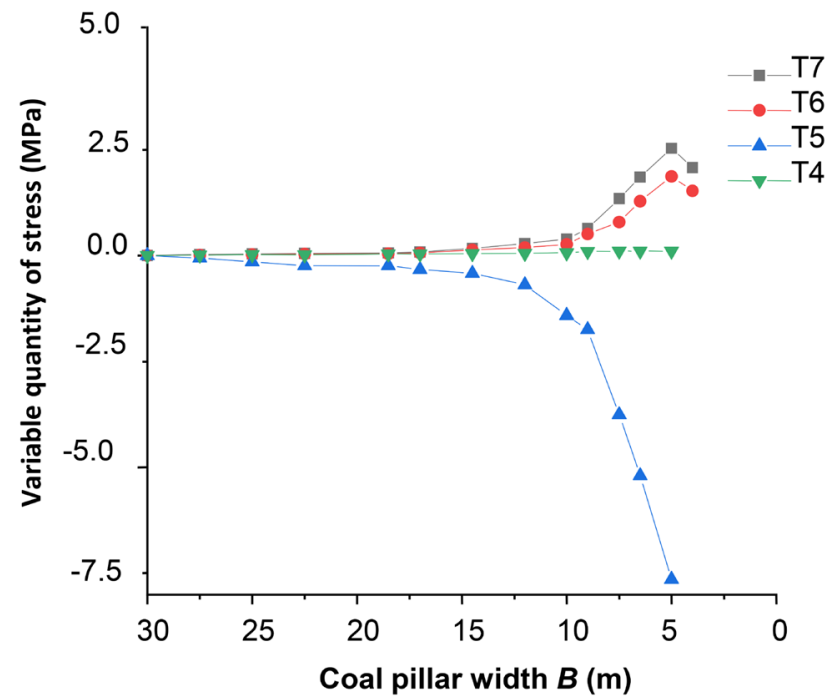

Fig. 11 Stress at various points in the roadway roof as a function of the coal pillar width and T7 begin to exhibit increasing pressure when the width of the coal pillar is $9 \mathrm{~m}$. The pressure increases suddenly when the coal pillar width is $7.5 \mathrm{~m}$, and the maximum increase is achieved when the coal pillar width is $5 \mathrm{~m}$. The maximum values are $2.5 \mathrm{MPa}$ and $1.8 \mathrm{MPa}$, respectively. Due to the stress concentration phenomenon caused by the slipping of the roof surrounding rock along the fault plane, plastic failure and instability of the roof of the roadway at T6 and T7 occur. When $B$ is $5 \mathrm{~m}$, the collapse of the surrounding rock causes the corresponding pressure sensor to loosen and fall off.

\subsubsection{Analysis of the change in the surrounding rock stress near the fault}

Stress sensors T2, T3 and T7 are positioned near the fault. The relationship between the stress increment and the coal pillar width is shown in Fig. 12. When the width of the coal pillar is larger than $20 \mathrm{~m}$, the stress increments at T2, T3, and $\mathrm{T} 7$ are basically zero. When the width of the coal pillar is between 10 and $20 \mathrm{~m}$, the rates of increase in the stress of T3, T2, and T7 increase in turn, but the maximum stress increment at this stage is less than $0.75 \mathrm{MPa}$. When the width of the coal pillar is between 5 and $10 \mathrm{~m}$, the rate of increase in the stress at $\mathrm{T} 2$ is accelerated, and the stress begins to increase suddenly when the width of the coal pillar is $7.5 \mathrm{~m}$. When the width of the coal pillar is $5 \mathrm{~m}$, the stress increments of $\mathrm{T} 2, \mathrm{~T} 3$, and $\mathrm{T} 7$ reach the maximum values, which are $3.5 \mathrm{MPa}, 3.1 \mathrm{MPa}$, and $2.5 \mathrm{MPa}$, respectively, and plastic failure begins at the bottom of the coal pillar.

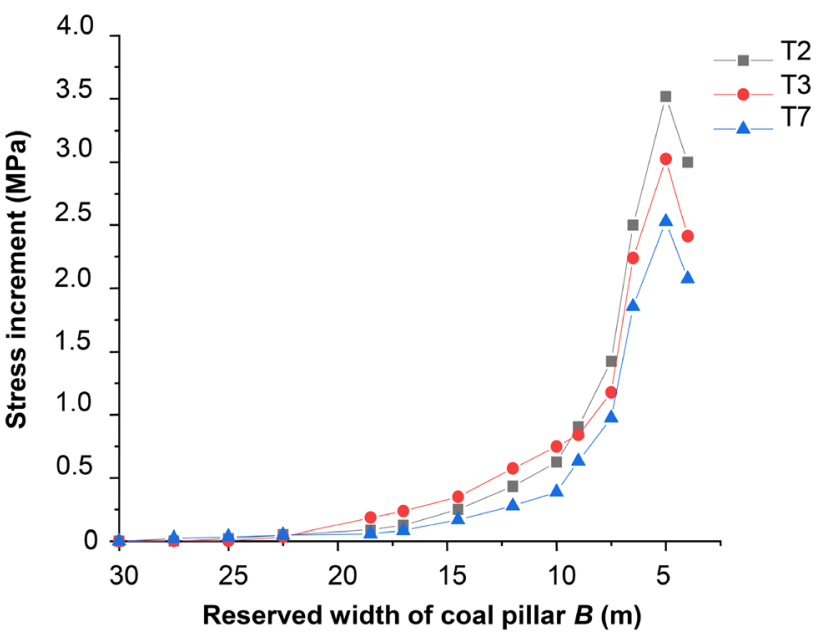

Fig. 12 Stress at various points of coal pillars as a function of the coal pillar width 


\subsubsection{Analysis of the stress change at the fault plane}

Pressure sensors T1, T5, T8, and T9 collect stress data at the fault plane. The relationship between the stress increment and the coal pillar width is shown in Fig. 13. The stress at $\mathrm{T} 1$ gradually increases, and the stress increases slowly when the width of the coal pillar is less than $10 \mathrm{~m}$. When the width of the coal pillar is $5 \mathrm{~m}$, the stress reaches a maximum value of $0.64 \mathrm{MPa}$. The stress at monitoring points $\mathrm{T} 5, \mathrm{~T} 8$, and $\mathrm{T} 9$ gradually decreases, and the rate of stress reduction accelerates at a coal pillar width of $17 \mathrm{~m}$. When the measuring point of the $\mathrm{T} 9$ pressure sensor is at a coal pillar width of $7.5 \mathrm{~m}$, the stress decreases to a minimum value of 3.8 MPa. When the coal pillar width is $6 \mathrm{~m}$, the stress decreases to a minimum of $5.9 \mathrm{MPa}$ at T8. This finding is basically consistent with the surrounding rock pressures at $\mathrm{T} 5, \mathrm{~T} 6$, and $\mathrm{T} 7$ in the hanging wall of the fault. When the coal pillar width is $5 \mathrm{~m}$, the stress decreases to a minimum of $7.7 \mathrm{MPa}$ at $\mathrm{T} 5$. The decrease in stress at the T5, T8, and T9 measuring points is due to the excessively narrow coal pillar, which causes the footwall surrounding rock to tend to collapse and form cracks. The T9 pressure sensor located in the main roof is loosened and falls off first, then T8 in the immediate roof falls off, and finally, T5 at the roof of the roadway falls off. Therefore, the narrower the coal pillar widths, the lower the clockwise-rotating tension cracks form in the surrounding wall rock, which may cause the surrounding rock of the roof to overturn and the roof on the right side of the fault and the right working slope of the roadway to deform plastically and become unstable overall.

Based on the above analysis, the initial and sudden increase in the vertical displacement and the vertical strain curve of the surrounding rock corresponds to a coal pillar

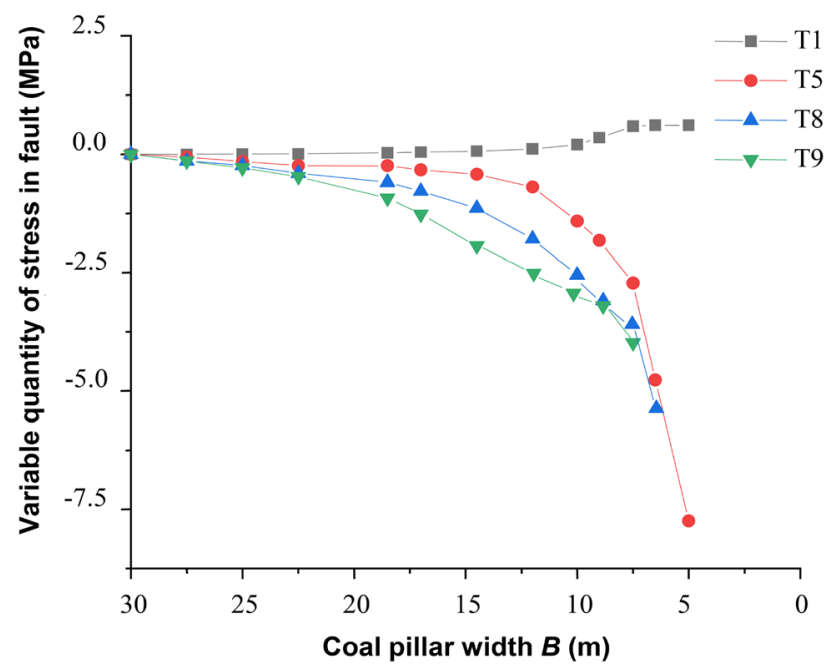

Fig. 13 Stress at various points along the fault plane as a function of the coal pillar width width of $10 \mathrm{~m}$, while the sudden change in the stress of the surrounding rock near the fault corresponds to a coal pillar width of $7.5 \mathrm{~m}$. Considering the support action of the roadway, the roadway is designed $7.5 \mathrm{~m}$ from the fault plane.

\section{Engineering practice}

As shown in Fig. 14, working face 101 of the Baiyangling Coal Mine is buried at a depth of $400 \mathrm{~m}$, with an average thickness of $4 \mathrm{~m}$. The roof and floor are mudstone or sandy mudstone. The haulage roadway of the mining face working is adjacent to the normal fault F3 and is located in the coal seam of the footwall. The section of the roadway is designed to be rectangular. The width of the roadway is $5.5 \mathrm{~m}$, the height is $3.8 \mathrm{~m}$, and the sectional area is 20.9 $\mathrm{m}^{2}$. Coal seam mining is carried out in the hanging wall of the normal fault. The roadway is $7.5 \mathrm{~m}$ from the fault plane. The roadway is supported by anchor nets and anchor cables. The pre-tightening force of the anchor is at least $200 \mathrm{KN}$, and the tensile force of the anchor cable is at least $100 \mathrm{kN}$. The roof adopts metal anchors. The specifications of the anchors are $\varphi=20 \mathrm{~mm}$ and $l=2300 \mathrm{~mm}$, with row and column spacings of $800 \mathrm{~mm}$ and $800 \mathrm{~mm}$. The specifications of the anchor cables are $\varphi=17.82 \mathrm{~mm}$ and $l=9000 \mathrm{~mm}$, with row and column spacings of $1600 \mathrm{~mm}$ and $800 \mathrm{~mm}$, and a single hydraulic prop with an initial support force of at least $90 \mathrm{kN}$ is used. The roadway on the side of the mining coal wall is supported by fibre-reinforced polymer (FRP) anchors and plastic steel mesh. The specifications of the anchors are $\varphi=20 \mathrm{~mm}$ and $l=2000 \mathrm{~mm}$, with row and column spacings of $1600 \mathrm{~mm}$ and $800 \mathrm{~mm}$. The roadway is supported by another group of anchor nets, and the specifications of the metal anchors of the anchor nets are $\varphi=20 \mathrm{~mm}$ and $l=2300 \mathrm{~mm}$, with row and column spacings of $800 \mathrm{~mm}$ and $800 \mathrm{~mm}$. The

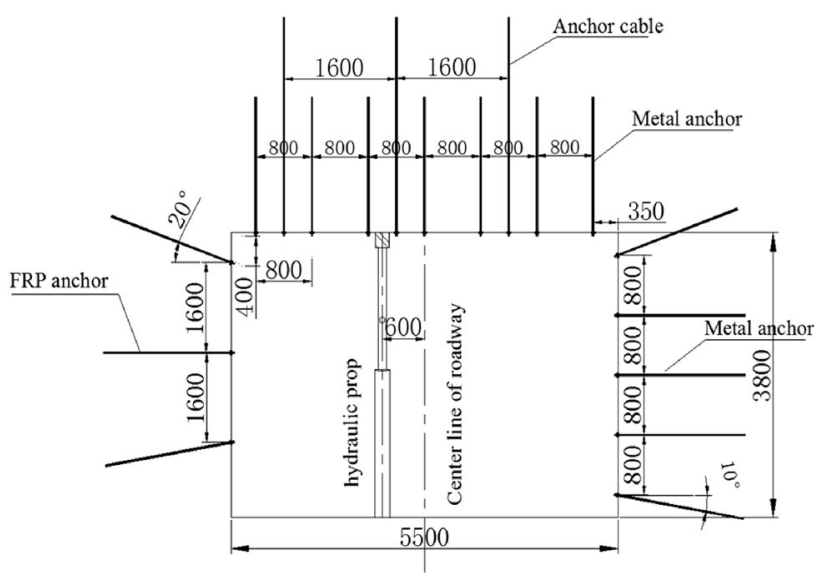

Fig. 14 Design drawing of the roadway section support, mm 
related deformation of the roadway was monitored after the excavation, as shown in Fig. 14.

Figure $15 \mathrm{a}$ and $\mathrm{b}$ show the curve of the roof sagging of the mining roadway and the curve of the falling rate of the roof, respectively. Figure $15 \mathrm{c}$ and $\mathrm{d}$ show curves of the deformation amount and deformation rate of the working slope in the coal pillar of the fault. On-site monitoring shows that the maximum amount of subsidence of the roof is $48 \mathrm{~mm}$ and that the roof becomes stable after excavation for 55 days. The maximum deformation of the coal pillar is $22 \mathrm{~mm}$, and the coal pillar stabilizes after 60 days of excavation. During the process of coal mining, the surrounding rock deformation is small, and the stability is good. A $7.5 \mathrm{~m}$ coal pillar width is left, and the abovementioned support measures are used to effectively control the deformation and failure of the surrounding rock of the mining roadway.

\section{Conclusions}

(1) The vertical displacement of the surrounding rock near the fault increases with the narrowing of the coal pillar width. When the coal pillar width is less than $10 \mathrm{~m}$, the vertical displacement increases

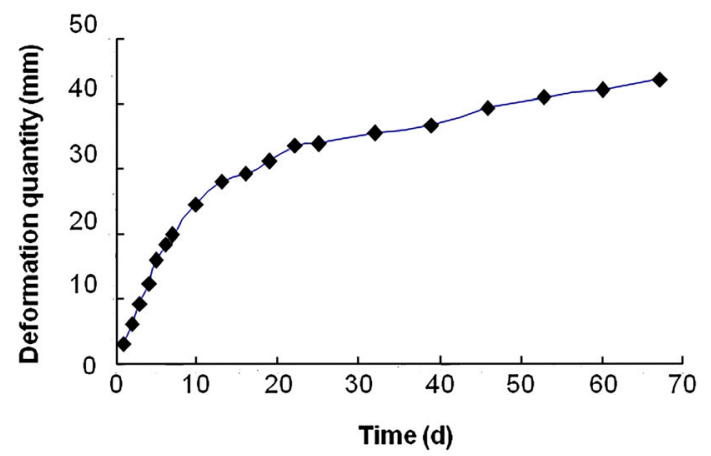

(a) Curve of roof sagging

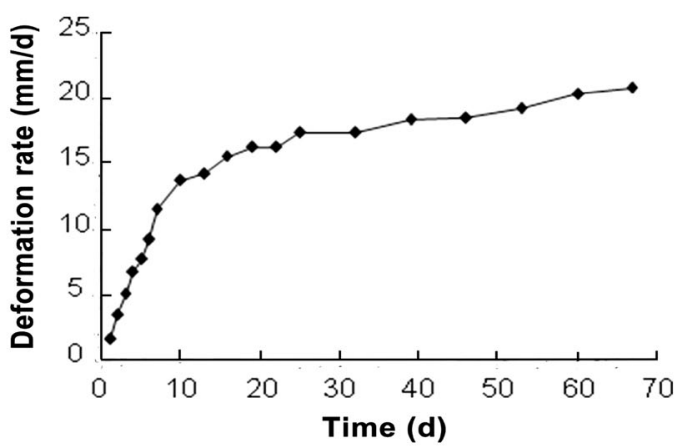

(c) Curve of coal pillar deformation suddenly. When the width of the coal pillar reaches $5 \mathrm{~m}$, the vertical displacement of the coal pillar reaches $50 \mathrm{~cm}$, the roadway exhibits rib spalling, the coal bodies in the coal pillars outburst, and the immediate roof collapses

(2) The vertical strain of the surrounding rock near the fault increases with the narrowing of the coal pillar width. When the coal pillar width is less than $10 \mathrm{~m}$, the vertical strain of the coal pillar increases suddenly. When the width of the coal pillar is $5 \mathrm{~m}$, the surrounding rock of the roof has a nonuniformly distributed plastic zone, and the equilibrium hinge of the massive rock mass cannot be formed.

(3) When the width of the coal pillar is $7.5 \mathrm{~m}$, the pressure of the surrounding rock near the footwall of the fault increases suddenly, but the stress at the location of the fault hanging wall pressure sensor T4 slightly increases by $0.35 \mathrm{MPa}$. When the footwall does not form an equilibrium hinge, part of the load disturbance is still transmitted to the hanging wall through the friction along the fault during the sliding of the roof caving, which causes the hanging wall to displace and partially collapse. When the width of the coal pillar is $5 \mathrm{~m}$, the steep stress gradient of the lower plate near T5 suddenly decreases until it is

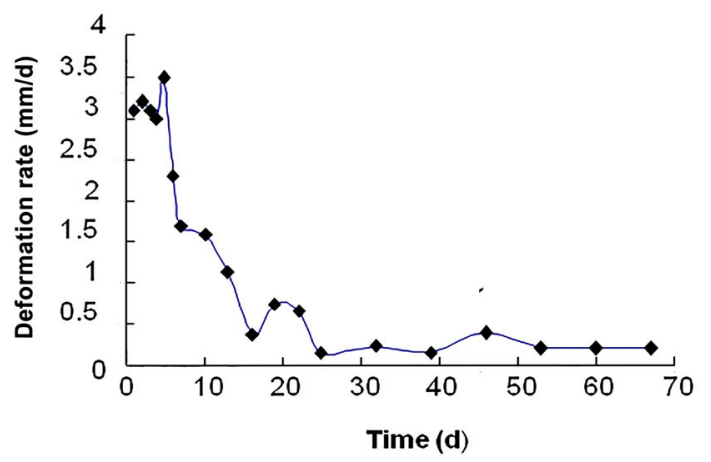

(b) Curve of the roof sagging rate

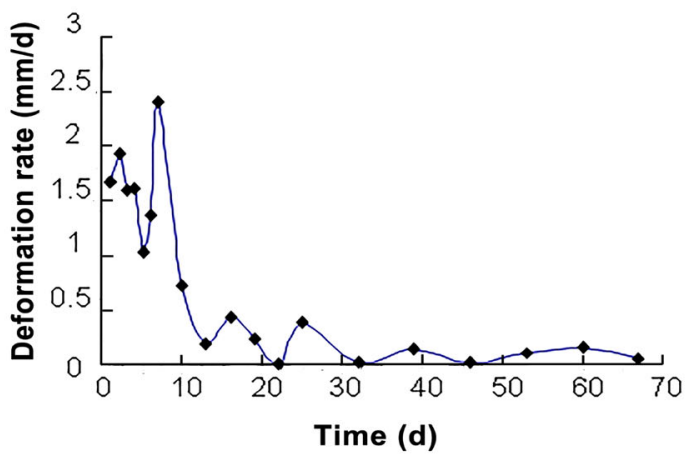

(d) Curve of coal pillar deformation rate

Fig. 15 Deformation monitoring of the roadway 
pulled and cracked; however, due to the collapse of the overlying rock strata, the stresses at the positions of the roof plates where $\mathrm{T} 6$ and $\mathrm{T} 7$ are located cause the pressure to increase suddenly, resulting in failure and instability.

(4) The 101 working face of the Baiyangling Coal Mine includes a roadway $7.5 \mathrm{~m}$ from the fault plane. Onsite monitoring suggests that the maximum subsidence of the roof is $48 \mathrm{~mm}$ and that the roof becomes stable after 55 days of excavation. The maximum amount of coal pillar deformation observed is $22 \mathrm{~mm}$, and the coal pillar becomes stable after 60 days of excavation. During the process of coal mining, the surrounding rock deformation is small, and the stability is good. A $7.5 \mathrm{~m}$ coal pillar width is left, and the abovementioned support measures are used to effectively control the deformation and failure of the surrounding rock of the mining roadway.

Acknowledgements The authors acknowledge the support of the China National Key R \& D Program Project (2017YFC1503102), the National Natural Science Foundation of China (No. 51704143) and the Natural Science Foundation of Liaoning Province of China (2020MS-302).

\section{Compliance with ethical standards}

Conflicts of interest The authors claim no conflicts of interest.

Ethical standards The experiments comply with the current laws of the country in which they were performed.

Open Access This article is licensed under a Creative Commons Attribution 4.0 International License, which permits use, sharing, adaptation, distribution and reproduction in any medium or format, as long as you give appropriate credit to the original author(s) and the source, provide a link to the Creative Commons licence, and indicate if changes were made. The images or other third party material in this article are included in the article's Creative Commons licence, unless indicated otherwise in a credit line to the material. If material is not included in the article's Creative Commons licence and your intended use is not permitted by statutory regulation or exceeds the permitted use, you will need to obtain permission directly from the copyright holder. To view a copy of this licence, visit http://creativecommons. org/licenses/by/4.0/.

\section{References}

Chen X, Li W, Yan X (2012) Analysis on rock burst danger when fully-mechanized caving coal face passed fault with deep mining. Saf Sci. https://doi.org/10.1016/j.ssci.2011.08.063

Dai J, Jiang J (2016) Influence of mining sequence of hanging wall and foot wall on mining-induced stress of fault coal pillar. J Min Saf Eng 33:35-41. https://doi.org/10.13545/j.cnki.jmse.2016.01. 006
Das AJ, Mandal PK, Sahu SP, Kushwaha A, Bhattacharjee R, Tewari $S$ (2018) Evaluation of the effect of fault on the stability of underground workings of coal mine through DEM and statistical analysis. J Geol Soc India 92:732-742. https://doi.org/10.1007/ s12594-018-1096-2

Islam MR, Shinjo R (2009) Mining-induced fault reactivation associated with the main conveyor belt roadway and safety of the Barapukuria coal mine in Bangladesh: constraints from BEM simulations. Int J Coal Geol. https://doi.org/10.1016/j.coal.2009. 06.007

Ji HG, Ma HS, Wang JA, Zhang YH, Cao H (2012) Mining disturbance effect and mining arrangements analysis of nearfault mining in high tectonic stress region. Saf Sci. https://doi. org/10.1016/j.ssci.2011.08.062

Jiang J, Wu Q, Qu H (2014) Evolutionary characteristics of mining stress near the hard-thick overburden normal faults. J Min Saf Eng 31:881-887. https://doi.org/10.13545/j.issn1673-3363.2014. 06.009

Kumar A, Kumar D, Singh Arun K, Ram S, Kumar R, Gautam A, Singh R, Singh AK (2019) Roof sagging limit in an early warning system for safe coal pillar extraction. Int J Rock Mech Min Sci. 123:104-131. https://doi.org/10.1016/j.ijrmms.2019. 104131

Li Z, Dou L, Cai W, Wang G, He J, Gong S, Ding Y (2014) Investigation and analysis of the rock burst mechanism induced within fault-pillars. Int J Rock Mech Min Sci. https://doi.org/10. 1016/j.ijrmms.2014.03.014

Lu C-P, Liu B, Liu B, Liu Y, Wang H-Y, Zhang H (2019) Anatomy of mining-induced fault slip and a triggered rockburst. Bull Eng Geol Environ. https://doi.org/10.1007/s10064-019-01464-8

Ma S, Jin G, Pan Y (2002) Deformation measurement method for rock materials based on natural speckle pattern. Chinese J Rock Mech Eng 21:792-796

Pan YS, Wang LG, Zhang MT, Xue BT (1998) The theoretical and testing study of fault rock burst. Chinese J Rock Mech Eng 17:642-649

Piotr M, Łukasz O, Piotr B (2017) Modelling the small throw fault effect on the stability of a mining roadway and its verification by in situ investigation. Energies 10:2082. https://doi.org/10.3390/ en10122082

Qian M, Miao X, He F (1994) Analysis the key block of "masonry beam" structure instope. J China Coal Soc 19:557-563

Sainoki A, Mitri HS (2017) Influence of mining activities on the reactivation of a footwall fault. Arabi J Geosci. https://doi.org/ 10.1007/s12517-017-2913-4

Singh R, Chapman DP, Atkinson KB (1997) Machine vision for dimensional measurements in mines. Geotech Geol Eng 15:185-203. https://doi.org/10.1007/BF00880824

Singh R, Singh TN (1999) Investigation into the behaviour of a support system and roof strata during sublevel caving of a thick coal seam. Geotech Geol Eng 17:21-35. https://doi.org/10.1023/ A: 1008853914726

Wang C, Cao A, Zhu G, Jing G, Li J, Chen T (2017) Mechanism of rock burst induced by fault slip in an island coal panel and hazard assessment using seismic tomography: a case study from Xuzhuang colliery Xuzhou, China. Geosci J. https://doi.org/10. 1007/s12303-016-0065-2

Wang H, Jiang Y, Xue S, Mao L, Lin Z, Deng D, Zhang D (2016) Influence of fault slip on mining-induced pressure and optimization of roadway support design in fault-influenced zone Journal of Rock Mechanics and Geotechnical. Engineering 8:660-671. https://doi.org/10.1016/j.jrmge.2016.03.005

Wang H, Shi R, Lu C, Jiang Y, Deng D, Zhang D (2019) Investigation of sudden faults instability induced by coal mining. Saf Sci 115:256-264. https://doi.org/10.1016/j.ssci.2019.01.019 
Yang J, Wang H, Wang Y, Liu B, Hou S, Cheng Y (2019) Stability analysis of the entry in a new mining approach influenced by roof fracture position. Sustainability 11:6349. https://doi.org/10. 3390/su11226349

Yin H, Sang S, Xie D, Zhao H, Li S, Li H, Zhuang X (2019) A numerical simulation technique to study fault activation characteristics during mining between fault bundles. Environ Earth Sci. https://doi.org/10.1007/s12665-019-8142-2

Zhang S, Zhang D, Wang H, Liang S (2018) Discrete element simulation of the control technology of large section roadway along a fault to drivage under strong mining. J Geophys Eng. 15:2642-2657. https://doi.org/10.1088/1742-2140/aae052 